\title{
CD40 activation in human pancreatic islets and ductal cells
}

\author{
D. Klein • F. Timoneri $\cdot$ H. Ichii $\cdot$ C. Ricordi • \\ R. L. Pastori
}

Received: 6 March 2008 / Accepted: 9 June 2008 / Published online: 26 July 2008

(C) Springer-Verlag 2008

\begin{abstract}
Aims/hypothesis CD40 expression on non-haematopoietic cells is linked to inflammation. We previously reported that CD40 is expressed on isolated human and non-human primate islets and its activation results in secretion of IL-8, macrophage inflammatory protein 1-beta (MIP-1 $\beta$ ) and monocyte chemoattractant protein-1 (MCP-1) through nuclear factor- $\mathrm{kB}$ and extracellularly regulated kinases $1 / 2$ pathways. The objective of this study was to identify the pattern of gene expression, and to study viability and functionality affected by CD40-CD40 ligand (CD40L) interaction in human islets. Furthermore, we have studied the CD40-mediated cytokine/chemokine profile in pancreatic ductal cells, as they are always present in human islet transplant preparations and express CD40 constitutively.

Methods CD40-CD40L gene expression modulation was studied by microarray on islet cells depleted of ductal cells. Selected genes were validated by quantitative RT-PCR. The cytokine profile in purified ductal cells was evaluated by Luminex technology, based on the use of fluorescent-coated beads, known as microspheres, and capable of multiplex detection of proteins from a single sample. Glucosestimulated insulin secretion and islet viability were assessed by perifusion and 7-aminoactinomycin D membrane exclusion, respectively.

Results Statistical analysis of microarrays identified 30 genes exhibiting at least a 2.5 -fold increase across all replicate arrays. The majority of them were related to oxidative stress/inflammation. Prominently upregulated were chemokine C-X-C motif ligand 1 (CXCL1), CXCL2
\end{abstract}

D. Klein and F. Timoneri contributed equally to this study

D. Klein $\cdot$ F. Timoneri $\cdot$ H. Ichii $\cdot$ C. Ricordi $\cdot$ R. L. Pastori $(\bowtie)$

Diabetes Research Institute,

University of Miami Leonard M. Miller School of Medicine,

1450 NW 10th Avenue,

Miami, FL 33136, USA

e-mail: rpastori@med.miami.edu and CXCL3 belonging to the CXC family of chemokines related to IL-8. CD40-mediated CXCL1 secretion was confirmed by ELISA. The viability or in vitro function was not affected by CD40 activation. In addition to previously reported IL-8, MIP-1 $\beta$ and MCP-1, CD40 stimulation in ductal cells produced IL- $1 \beta$, IFN- $\gamma$, TNF- $\alpha$, granulocyte colony-stimulating factor and granulocyte-macrophage colony-stimulating factor.

Conclusions/interpretation CD40 activation in islets and ductal cells produces cytokines/chemokines with a broadspectrum range of biological functions.

Keywords CD40 - Chemokines · Cytokines · Ductal cells . Inflammation · Insulin · Islets of Langerhans · Microarray · Quantitative RT-PCR

$\begin{array}{ll}\text { Abbreviations } \\ \text { 7-AAD } & \text { 7-aminoactinomycin D } \\ \text { CD40L } & \text { CD40 ligand } \\ \text { CXCL1 } & \text { chemokine C-X-C motif ligand 1 } \\ \text { CXCL2 } & \text { chemokine C-X-C motif ligand 2 } \\ \text { ERK1/2 } & \text { extracellularly regulated kinases } 1 / 2 \\ \text { G-CSF } & \text { granulocyte colony-stimulating factor } \\ \text { GM-CSF } & \text { granulocyte-macrophage colony-stimulating } \\ & \text { factor } \\ \text { ICAM-1 } & \text { intercellular adhesion molecule } \\ \text { KC } & \text { mouse homologue of human CXCL1 } \\ \text { MCP-1 } & \text { monocyte chemoattractant protein-1 } \\ \text { MIP-1 } \beta & \text { macrophage inflammatory protein 1-beta } \\ \text { NF- } \mathrm{B} B & \text { nuclear factor- } \mathrm{KB} \\ \text { RQ } & \text { relative quantification }\end{array}$

\section{Introduction}

CD40 receptor has a critical role in the activation of immune responses and was first identified and characterised in leucocytes [1]. Its importance in allograft rejection and 
autoimmunity has been widely accepted $[2,3]$. Furthermore, prevention of CD40-CD40 ligand (CD40L) interaction prolongs allogeneic islet graft survival in rodents and non-human primates $[4,5]$. However, recently it has been demonstrated that CD40 is also expressed in non-immune cells of diverse embryonic origin and function. The role of CD40 in non-haematopoietic cells is not yet completely understood; in general it has been linked to non-specific inflammatory states [6-10]. Examples of CD40-mediated survival have been reported in some cell types [11, 12].

We have previously reported that CD40 is expressed in murine and human pancreatic beta cells and that its expression is upregulated by a cocktail of diabetogenic cytokines (IL-1 $\beta$, TNF- $\alpha$ and IFN- $\gamma$ ) [13]. The stimulation of CD40 receptor on islet cells increases extracellularly regulated kinases 1/2 (ERK1/2)- and nuclear factor- $\mathrm{KB}$ (NF-kB)-dependent inflammatory signals, resulting in secretion of cytokines such as IL-6, IL-8, macrophage inflammatory protein 1-beta (MIP-1 $\beta$ ) and monocyte chemoattractant protein-1 (MCP-1) [14]. Furthermore, CD40-CD40L interaction in islet cells upregulates the expression of intercellular adhesion molecule-1 (ICAM-1), which is associated with inflammation [15].

In this study, we have identified genes that are differentially expressed by CD40L engagement in human islet cells using gene array technology and have investigated the influence of CD40-CD40L interaction on islet viability and in vitro function. Moreover, pancreatic ductal cells are always present in human islet preparations and express CD40 receptor constitutively [16], and therefore we have also studied the CD40-mediated secretion of cytokines/ chemokines in ductal cells.

\section{Methods}

Islets of Langerhans were isolated from human pancreases obtained from deceased multiorgan donors (between the ages of 23 and 61 years) for which consent for research was given, using the automated method [17]. Human islets were obtained from the Diabetes Research Institute cell-processing facility and from participating centres of the National Institute of Health Islet Cell Resources (ICR). Islets were used under protocols reviewed and approved by the University of Miami Institutional Review Board (IRB).

Isolation of islet cells and ductal cells using magnetic beads technology

The separation of cell subsets (i.e. endocrine, ductal cells) from human islet preparations was performed as previously described [14]. Briefly, islets were enzymatically dissociated for $10-12 \mathrm{~min}$ at $37^{\circ} \mathrm{C}$ into single-cell suspensions
(Accutase; Innovative Cell Technologies, San Diego, CA, USA). Enzymatic activity of Accutase was deactivated by addition of an equal volume of fetal bovine serum. Dissociated islet cells were incubated for $15 \mathrm{~min}$ on ice with mouse anti-carbohydrate antigen CA19-9 pan-ductal membrane antibody (1:100 dilution; Novocastra, Newcastle, UK).The two washes performed at the end of the incubation were followed by incubation on ice for 1520 min with MACS goat anti-mouse IgG microbeads (4:1 dilution; Miltenyi Biotec, Auburn, CA, USA). The cell suspension was passed twice through a magnetic column. The efficiency of depletion was evaluated by flow cytometry (FacsCalibur; Becton Dickinson, Mountain View, CA, USA) with anti-mouse Alexa fluor 488-conjugated secondary antibody (1:300 dilution; Invitrogen, La Jolla, CA, USA). The purity of the CA19-9-negative islet cell fraction was $>99 \%$. Viability of depleted islet cells after $24 \mathrm{~h}$ was $70 \pm 5 \%$ depending on the quality of the starting preparation. The assessment of cell death was performed with 7-aminoactinomycin D (7-AAD; Invitrogen). Depleted islet cell populations were screened for other CD40expressing cells, such as B cells and dendritic cells (CD19 and CD11c, respectively; BD-Pharmingen, La Jolla, CA, USA) and monocytes (CD14; R\&D Systems, Minneapolis, $\mathrm{MN}$, USA), which were detected only in negligible quantities [14]. The CA19-9-positive fraction contained $>97 \%$ pure ductal cells.

Activation of CD40 receptor in islets or ductal cells

Entire human islets, islet cells and ductal cells were incubated for various lengths of time with CD40L $(1 \mu \mathrm{g} / \mathrm{ml} \mathrm{recombi-}$ nant human soluble CD40L plus $1 \mu \mathrm{g} / \mathrm{ml}$ enhancer of ligands) (Alexis Biochemicals, San Diego, CA, USA), according to the manufacturer's instructions. Henceforth, every time CD40L is mentioned the enhancer is included in the treatment at the above-stated concentration. We have tested the possibility that the enhancer of ligands, used in all our experiments together with CD40L, might have an effect on cytokine and insulin secretion or RNA transcription. We have not found any such effect.

Gene array analysis

RNA preparation Depleted human islet cells were treated for 5-6 h with CD40L; controls remained untreated. Total RNA was extracted and purified using PicoPure Kit (Arcturus Engineering, Mountain View, CA, USA) according to the manufacturer's instructions and then quantified with a Nanodrop spectrophotometer (Thermo Fisher Scientific, Waltham, MA, USA). The RNA was qualified on an Agilent 2100 Bioanalyzer (Caliper Technologies, Mountain View, CA, USA). Three independent experiments were performed. 
Amplification and labelling of RNA RNA was amplified with an Amino Allyl MessageAmp aRNA Amplification Kit (Cat. no. 1753; Ambion, Austin, TX, USA) and labelled with Cy3- and Cy5-NHS ethers (Cat. no. PA23001 and PA25001, respectively; Amersham, Pittsburgh, PA, USA). Concentration of labelled aRNA and labelling efficiency were determined spectrophotometrically. The equal amounts of labelled aRNA were hybridised to Agilent Whole Human Genome Oligo microarrays (Cat. no. $\mathrm{G} 4112 \mathrm{~A}$ ) for $17 \mathrm{~h}$ at $60^{\circ} \mathrm{C}$ following the manufacturer's instructions. All experiments were performed using a 'dye flip' method, where replicate hybridisations of the same sample and control are performed in each dye direction.

Image analysis and data processing The microarrays were scanned at $10 \mu \mathrm{m}$ resolution using a GenePix 4000A scanner (Axon Instruments/Molecular Devices, Union City, CA, USA) and the resulting images analysed with GenePix Pro 5.1 software package (Axon Instruments). Data extracted from the images were transferred to the Acuity 4.0 software (Axon Instruments) for normalisation and statistical analysis. Each array was normalised for signal intensities locally and across the entire array, using Lowes normalisation. Features for further analysis were selected according to the following quality criteria: (1) at least $90 \%$ of the pixels in the spot had intensity higher than background plus 2 SDs; (2) $<2 \%$ saturated pixels in the spot; (3) signal-to-noise ratio (defined as ratio of the background subtracted from mean pixel intensity to SD of background) was $\geq 3$ for each channel; (4) the spot diameter was between 80 and $110 \mu \mathrm{m}$; and (5) the regression coefficient of ratios of pixel intensity was $\geq 0.6$.

To identify significantly expressed genes across all replicate arrays, one-class significant analysis of microarray (http://www-stat.stanford.edu/ tibs/SAM) was used with a false discovery rate $<5 \%$ and a fold change $>2.5$ [18]. All primary microarray data were submitted to the public database at the GEO website (http://www.ncbi.nlm.nih.gov/ geo/query/acc.cgi?token=drerrueuigoimvs\&acc=GSE8873).

Selected genes were classified into six broadly defined classes according to Gene Ontology category 'biological process' using Onto-Express (http://vortex.cs.wayne.edu/ Projects.html) [19].

Relative quantification real-time PCR

Human islet cells depleted of ductal cells were incubated with CD40L for $5 \mathrm{~h}$. Total RNA was isolated with an RNeasy kit (Qiagen, Valencia, CA, USA), treated with DNase I and used for cDNA synthesis. The assay was performed with a 7500 Fast Real-Time PCR system using TaqMan Universal PCR mix and TaqMan probes (Applied Biosystems, Foster City, CA, USA). We quantified the following genes: $B D K R B 1, B I R C 3, C X C L 1, C X C L 2$, CXCL3, IL17RB, IL23A, CCL20 (also known as MIP3-A) and $P L A U$. The PCR reactions were plated in triplicate using probes specific for each mRNA (Applied Biosystems). Relative quantification (RQ) determines the change in expression of target transcripts in a test sample (CD40Ltreated cells) relative to a calibrator sample (untreated controls). RQ was calculated via Applied Biosystems SDS software based on the equation $\mathrm{RQ}=2^{-\Delta \Delta C_{\mathrm{t}}}$, where $C_{\mathrm{t}}$ is the number of cycles at which amplification reaches a threshold determined by the software within the exponential amplification phase. $C_{\mathrm{t}}$ data were normalised to endogenous control $\beta$-actin.

\section{CXCL1 induction and detection}

Depleted islet cells were cultured in suspension at the density of 900,000 cells in $1 \mathrm{ml}$ Miami Medium no. 1A (MM1A, Cat. no. 98-021-CV; Mediatech-CellGro, Manassas, VA, USA). The cells were stimulated for $24 \mathrm{~h}$ at $37^{\circ} \mathrm{C}$ with CD40L. In order to confirm NF- $\mathrm{B}$ pathway involvement, an inhibitor of NF- $\mathrm{B}$ phosphorylation, Bay11-7082 (5 $\mu \mathrm{mol} / \mathrm{l}$; Biomol, Plymouth Meeting, PA, USA), was added once to the media $1 \mathrm{~h}$ prior to stimulation and maintained in the culture for the duration of the experiment. Secretion of the C-X-C motif ligand 1 (CXCL1) chemokine was determined by ELISA (R\&D Systems).

Islet cell viability

The entire human islets were incubated with CD40L for 48 and $96 \mathrm{~h}$. The islets were dissociated as described earlier and then stained with 7-AAD ( $1 \mu \mathrm{g} / \mathrm{ml}$ final dilution) to detect cell death. After 20 min of incubation, the samples were evaluated by flow cytometry.

In vitro islet function

Dynamic glucose-stimulated insulin secretion was performed on a customised perifusion apparatus (BioRep, Miami, FL, USA). Briefly, 100 islets treated in culture for $24 \mathrm{~h}$ with CD40L $(1 \mu \mathrm{g} / \mathrm{ml})$ were loaded in HEPES buffer into columns with Bio-Gel P-4Gell (Bio-Rad, Hercules, CA, USA) and pre-incubated with $3 \mathrm{mmol} / 1$ glucose in HEPES buffer for $45 \mathrm{~min}$, with a constant flow of $100 \mu \mathrm{l} / \mathrm{min}$. At the end of pre-incubation the islets were exposed sequentially to $3 \mathrm{mmol} / 1$ glucose $(5 \mathrm{~min}), 11 \mathrm{mmol} / 1$ glucose (10 $\mathrm{min}), 3 \mathrm{mmol} / \mathrm{l}$ glucose $(15 \mathrm{~min}), 25 \mathrm{mmol} / \mathrm{l} \mathrm{KCl}$ ( $5 \mathrm{~min}$ ), and finally again to $3 \mathrm{mmol} / \mathrm{l}$ glucose $(5 \mathrm{~min})$. The flow-through was collected in a 96 well plate $(1 \mathrm{~min}$ per well). At the end of perifusion the islets were washed out from the column using Tissue Protein Extraction Reagent (Pierce, Rockford, IL, USA) and DNA content was measured 
using Quant-It Pico Green (Invitrogen). Insulin levels in the collected samples were quantified by ELISA (Mercodia, Uppsala, Sweden) and results normalised to DNA content.

Cytokine/chemokine induction and secretion in pancreatic ductal cells

Human ductal cells were purified by positive selection using anti-CA19-9 antibody and conjugated magnetic bead cell separation. Pure ductal cells were cultured for $48 \mathrm{~h}$ to allow them to shed the magnetic beads. The medium was changed and CD40L $(1 \mathrm{mg} / \mathrm{ml})$ was added for a $24 \mathrm{~h}$ treatment. At the end of incubation, supernatant fractions were collected and concentrations of cytokines/chemokines determined using a Multi-Plex kit following the manufacturer instructions (Bio-Plex Platform Technology; Bio-Rad).

\section{Statistical analysis}

We used the Shapiro-Wilk normality test to determine if our results followed Gaussian distribution. Neither set of results passed completely the normality test. Therefore we analysed all the results using the Wilcoxon signed-rank test for paired, non-parametric samples. Only $p$ values $<0.05$ were considered statistically significant.

\section{Results}

Gene microarray studies

A combination of statistical analysis plus fold-change ranking of microarray experiments was used to determine a signature gene list regulated by CD40-CD40L interaction in human islet cells. Human islets were dissociated and islet cells depleted from CD40-expressing duct cells prior to incubation with CD40L. As we previously reported, the depleted fraction of islet cells contained negligible amounts of ductal cells, B cells, dendritic cells and monocytes [14]. Following Microarray Quality Control Consortium recommendations, we identified 30 transcripts increased at least 2.5 -fold within a false discovery rate $<5 \%$ in islet cells treated with CD40L. The genes were classified into six broadly defined classes according to Gene Ontology category 'Biological process' (Table 1) using Onto-Express (http://vortex.cs.wayne.edu/Projects.html) [19]. The categories are: (1) Inflammation, immune response, coagulation and oxidative stress (14 genes); (2) Apoptosis/survival (two genes); (3) Signal transduction (five genes); (4) Metabolism (two genes); (5) Transcription factors (two genes); and (6) Protein degradation (one gene). Four genes have unknown function.
Most of the genes were related to inflammation and oxidative stress. Included in this group were CCL4 (coding for MIP-1 $\beta$ ), ICAM1 (coding for ICAM-1), CCL2 (coding for MCP-1) and IL8, which we have previously described as regulated by CD40 activation in human islet cells [14]. Nine genes were selected and quantified by real-time PCR ( $n=7$ organ donors). Specific gene upregulation was confirmed in most preparations, even though with some variability within each human islet preparation: $B D K R B 1$ (4/7), BIRC3 (7/7), CXCL1 (7/7), CXCL2 (6/7), CXCL3 (7/ 7), IL17RB (7/7), IL23A (7/7) CCL20 (3/7) and PLAU (5/7) (Fig. 1). Statistical analysis using Wilcoxon's paired signed-rank test showed statistical significance for $B I R C 3$, $C X C L 1, C X C L 3, I L 17 R B$ and IL23A $(p=0.015)$ and for CXCL2 $(p=0.031)$ but not for BDKRB1 $(p=0.296), C C L 20$ $(p=0.579)$ and $P L A U(p=0.078)$. In either case the number of amplification cycles did not exceed 30, suggesting that the possibility of an artefact is at a minimum.

\section{CD40-mediated secretion of CXCL1 in islet cells}

In the gene array, the CXCL1 gene showed $>60$-fold upregulation. We investigated if the activation of islet cells with CD40L resulted in the secretion of CXCL1 as well. Supernatant fractions from pure human islet cells treated for $24 \mathrm{~h}$ with CD40L and the untreated controls, were assayed by ELISA for the presence of CXCL1. We found CD40mediated secretion of CXCL1 in all seven human islet preparations (Fig. 2). As reported by others [20-22], the production of CXCL1 was sharply decreased by a $1 \mathrm{~h}$ pretreatment with NF-kB pathway inhibitor, Bay 11-7082 (5 $\mu \mathrm{mol} / \mathrm{l})$ (results not shown).

Engagement of CD40 receptor in human islets neither induces cell death nor affects insulin secretion

In several reports the CD40 activation was linked with cell death [23-25]. We investigated if CD40 activation causes cell death in cultured islets. Entire human islets were incubated with CD40L for 48 and $96 \mathrm{~h}$. The cell death was evaluated by flow cytometry using the membrane-exclusion dye 7-AAD. Even though CD40L treatment induced secretion of cytokines/chemokines, and the islets remained up to $96 \mathrm{~h}$ in the resulting milieu, our data showed no detrimental changes in viability (Fig. 3a).

Recent reports indicate that glucose activates ERK1/2, which results in induction of insulin secretion [26]. Since CD40 stimulation in islets activates ERK1/2 as well [14], we hypothesised that engagement of CD40 could have an effect on insulin secretion. The perifusion studies of entire human islets indicated that CD40 activation has no effect on insulin secretion. The insulin secretion profiles of islets 
Table 1 List of genes identified by microarray as differentially expressed by CD40 activation in human islet cells $(n=3)$

\begin{tabular}{|c|c|c|c|}
\hline $\begin{array}{l}\text { Gene Bank } \\
\text { accession no. }\end{array}$ & $\begin{array}{l}\text { Gene } \\
\text { symbol }\end{array}$ & Gene name & $\begin{array}{l}\text { Fold } \\
\text { change }\end{array}$ \\
\hline \multicolumn{4}{|c|}{ Inflammation, immune response, coagulation } \\
\hline NM_001511 & $C X C L 1$ & Chemokine (C-X-C motif) ligand 1 & 69.0 \\
\hline NM_000584 & IL8 & Interleukin 8 & 23.9 \\
\hline NM_002089 & CXCL2 & Chemokine (C-X-C motif) ligand 2 & 15.2 \\
\hline NM_000576 & $I L 1 B$ & Interleukin 1 , beta & 14.2 \\
\hline NM_002090 & CXCL3 & Chemokine (C-X-C motif) ligand 3 & 8.5 \\
\hline NM_004591 & CCL20 & Chemokine (C-C motif) ligand 20 & 5.8 \\
\hline NM_006291 & TNFAIP2 & Tumour necrosis factor, alpha-induced protein 2 & 5.5 \\
\hline NM_002658 & PLAU & Plasminogen activator, urokinase & 4.1 \\
\hline NM_016584 & $I L 23 A$ & Interleukin 23 , alpha subunit p19 & 2.7 \\
\hline NM_002984 & CCL4 & Chemokine (C-C motif) ligand 4 & 2.6 \\
\hline NM_018725 & $I L 17 R B$ & Interleukin 17 receptor $\mathrm{B}$ & 2.5 \\
\hline AF117819 & $B D K R B 1$ & Bradykinin receptor $\mathrm{B} 1$ & 2.5 \\
\hline NM_000201 & ICAMI & Intercellular adhesion molecule 1 (CD54) & 2.5 \\
\hline NM_002982 & CCL2 & Chemokine (C-C motif) ligand 2 & 2.5 \\
\hline \multicolumn{4}{|c|}{ Apoptosis/survival } \\
\hline NM_001165 & $B I R C 3$ & Baculoviral IAP repeat-containing 3 & 20.6 \\
\hline NM_000636 & SOD2 & Superoxide dismutase 2 , mitochondrial & 2.9 \\
\hline \multicolumn{4}{|c|}{ Signal transduction } \\
\hline NM_020529 & NFKBIA & Nuclear factor of kappa light polypeptide gene enhancer in B cells inhibitor, alpha & 6.2 \\
\hline NM_005204 & $M A P 3 K 8$ & Mitogen-activated protein kinase kinase kinase 8 & 3.5 \\
\hline $\mathrm{BC} 014259$ & TIFA & TRAF-interacting protein with a forkhead-associated domain & 3.4 \\
\hline NM_002350 & $L Y N$ & v-yes-1 Yamaguchi sarcoma viral related oncogene homologue & 2.9 \\
\hline NM_005178 & $B C L 3$ & B cell CLL/lymphoma 3 & 2.5 \\
\hline \multicolumn{4}{|l|}{ Metabolism } \\
\hline NM_005114 & HS3ST1 & Heparan sulphate (glucosamine) 3-O-sulfotransferase 1 & 2.7 \\
\hline AK074235 & B3GNT5 & UDP-GlcNAc:betaGal beta-1,3- $N$-acetylglucosaminyl-transferase 5 & 2.5 \\
\hline \multicolumn{4}{|c|}{ DNA transcription } \\
\hline NM_005375 & $M Y B$ & v-myb myeloblastosis viral oncogene homologue (avian) & 2.9 \\
\hline ВC028013 & $R E L B$ & $\begin{array}{l}\text { v-rel reticuloendotheliosis viral oncogene homologue B, nuclear factor of kappa light polypeptide } \\
\text { gene enhancer in B cells } 3 \text { (avian) }\end{array}$ & 2.8 \\
\hline \multicolumn{4}{|c|}{ Genes involved in protein degradation } \\
\hline NM_006398 & $U B D$ & Ubiquitin D & 2.5 \\
\hline \multicolumn{4}{|l|}{ Unknown } \\
\hline NM_138397 & & & 6.8 \\
\hline NM_025079 & $Z C 3 H 12 A$ & Zinc finger $\mathrm{CCCH}$-type containing $12 \mathrm{~A}$ & 5.4 \\
\hline $\mathrm{BC} 033490$ & FAM150B & Hypothetical protein LOC285016 & 3.2 \\
\hline I_966514 & & & 2.9 \\
\hline
\end{tabular}

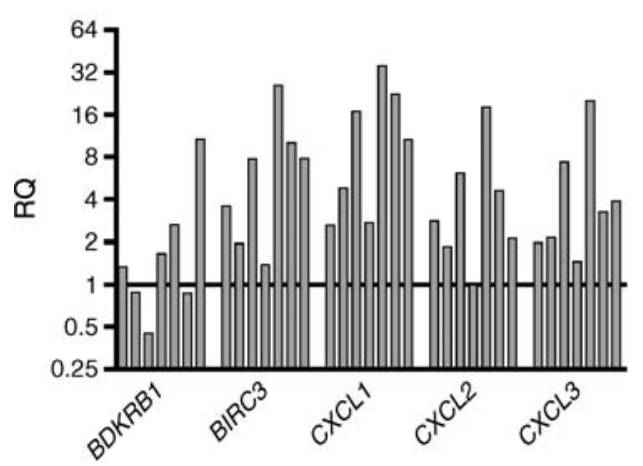

Fig. 1 Validation of selected genes using quantitative RT-PCR. Values are expressed as RQ, representing the change in expression of target transcripts (CD40L-treated cells) relative to untreated cells.

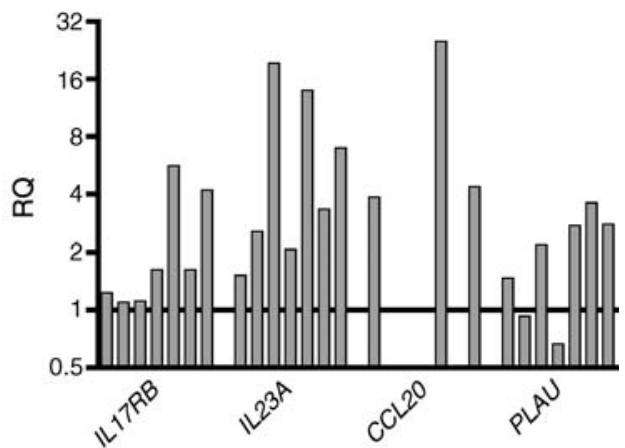

Islet cells depleted of ductal cells were treated with CD40L for $5 \mathrm{~h}$ before RT-PCR analysis ( $n=7$ human islet preparations). The horizontal line represents the threshold of activation 


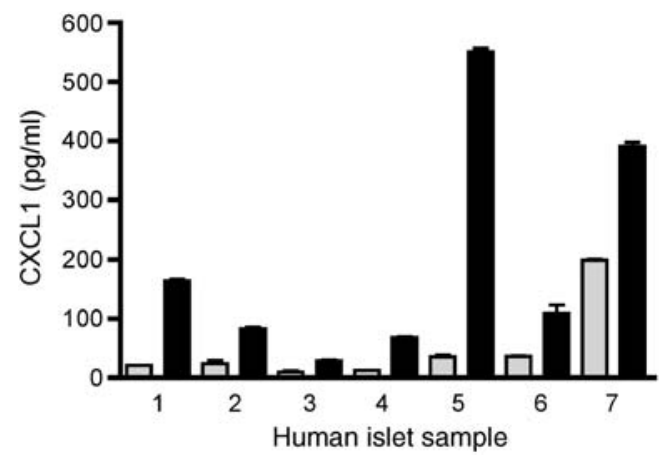

Fig. 2 Determination of CXCL1 secretion, induced by stimulation of CD40 receptor. The CXCL1 protein secretion from islet cells depleted of ductal cells activated for $24 \mathrm{~h}$ with CD40-CD40L was evaluated by ELISA. Grey and black bars represent control and CD40L-treated cells, respectively. Values are means \pm SD for each islet preparation. Wilcoxon signed-rank test for paired, non-parametric samples was used for statistical analysis $(p=0.01560)$. The islet preparations $(n=7)$ were different from the ones used in Fig. 1

stimulated with CD40L were similar to those of untreated islets (Fig. 3b).

CD40-mediated secretion of chemokines/cytokines in ductal cells

CD40 is constitutively expressed in pancreatic ductal cells [16], which are present in every human islet preparation. We determined the cytokine/chemokine expression profile in the supernatant fractions from the primary human ductal cells induced for $24 \mathrm{~h}$ with CD40L. Compared with untreated controls the CD40 engagement resulted in the increased secretion of MIP-1 $\beta$, IL-6, MCP-1, IL-8, CXCL1, TNF- $\alpha$, IL-1 $\beta$, IFN- $\gamma$, granulocyte colony-stimulating factor (G-CSF) and granulocyte-macrophage colony-stimulating factor (GMCSF) (Fig. 4).

\section{Discussion}

In this work we have used microarray technology to compile a signature gene list regulated by CD40-CD40L interaction in human pancreatic islet cells. We have identified a total of 30 upregulated and zero downregulated genes. We validated nine genes by quantitative RT-PCR. Even though some inter-islet preparation variability was observed (most likely due to the noxious effects activated by donor brain death and cold ischaemia time in the harvested pancreas), IL23A and CXCL1 were consistently upregulated in all individual preparations tested. IL-23A and IL-12 p40 subunits form the heterodimeric IL-23, which is necessary for expansion and survival of highly pathogenic Th17 lymphocyte subsets shown to be involved in the development and maintenance of chronic autoim- mune inflammation in the central nervous system and in joints [27]. In an islet transplant situation, it is conceivable that the level of cytokine production by human islet preparations after implantation into the recipient's liver may contribute to the initiation and maintenance of Th17 lymphocyte subsets and subsequently contribute to specialised immune activations (namely, allorejection and recurrence of autoimmunity), thereby negatively influencing the fate of the graft.

Our data indicate that CD40 mediates the secretion of CXCL1 by islet cells. CXCL1 belongs to the ELR-CXC chemokine subgroup, defined by the conserved sequence motif Glu-Leu-Arg (the ELR motif) at the N-terminal domain of the ligands. ELR-CXC chemokines are mainly chemotactic for neutrophils [28-30]. The CXCL1 gene contains regulatory transcription sequences including an NF-KB target sequence [31]. Inhibition of NF-KB has been shown to abolish CXCL1 secretion in other experimental settings [20-22], which is in agreement with our finding that CXCL1 secretion in islets is NF-KB-dependent. The role of CXCL1 in the recruitment of polymorphonuclear
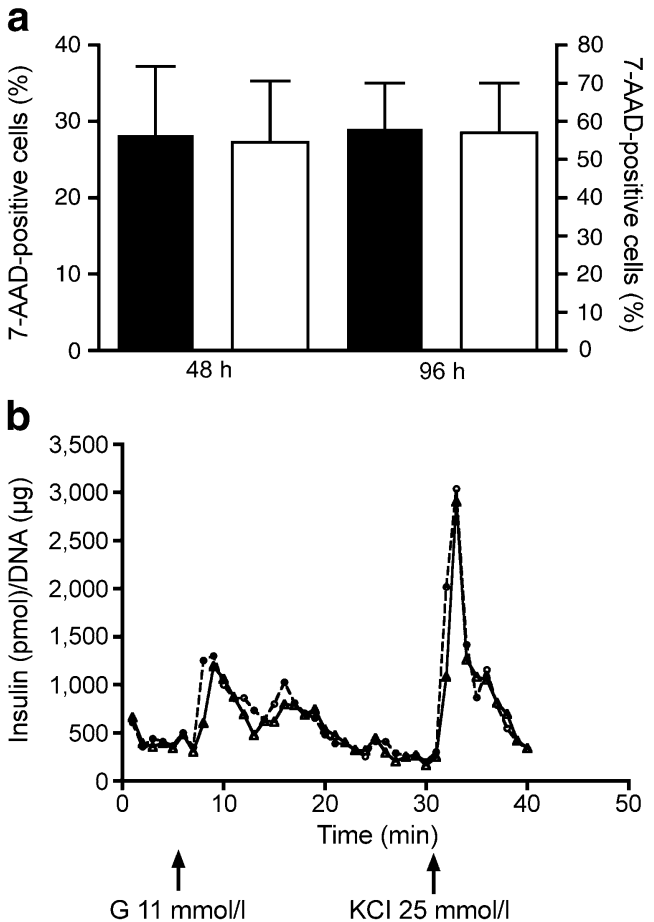

Fig. 3 Engagement of CD40 receptor in human islets does not induce either cell death or insulin release. a Islet death. Entire islets were treated for $48(n=6)$ and $96(n=3) \mathrm{h}$ with CD40L, and cell death was evaluated by 7-AAD staining and flow cytometry. Values for $48 \mathrm{~h}$ are represented on the left $y$-axis, and $96 \mathrm{~h}$ on the right $y$-axis. Black and white bars represent control and CD40L-treated islets, respectively. b Dynamic glucose-stimulated insulin release. Insulin assessment of perifusion of islet aliquots (100 islet equivalent) from untreated control islets (triangles, solid line) and from islets treated with CD40L (circles, dashed line) $(24 \mathrm{~h})$. The perifusion is representative of five independent experiments. G, glucose 

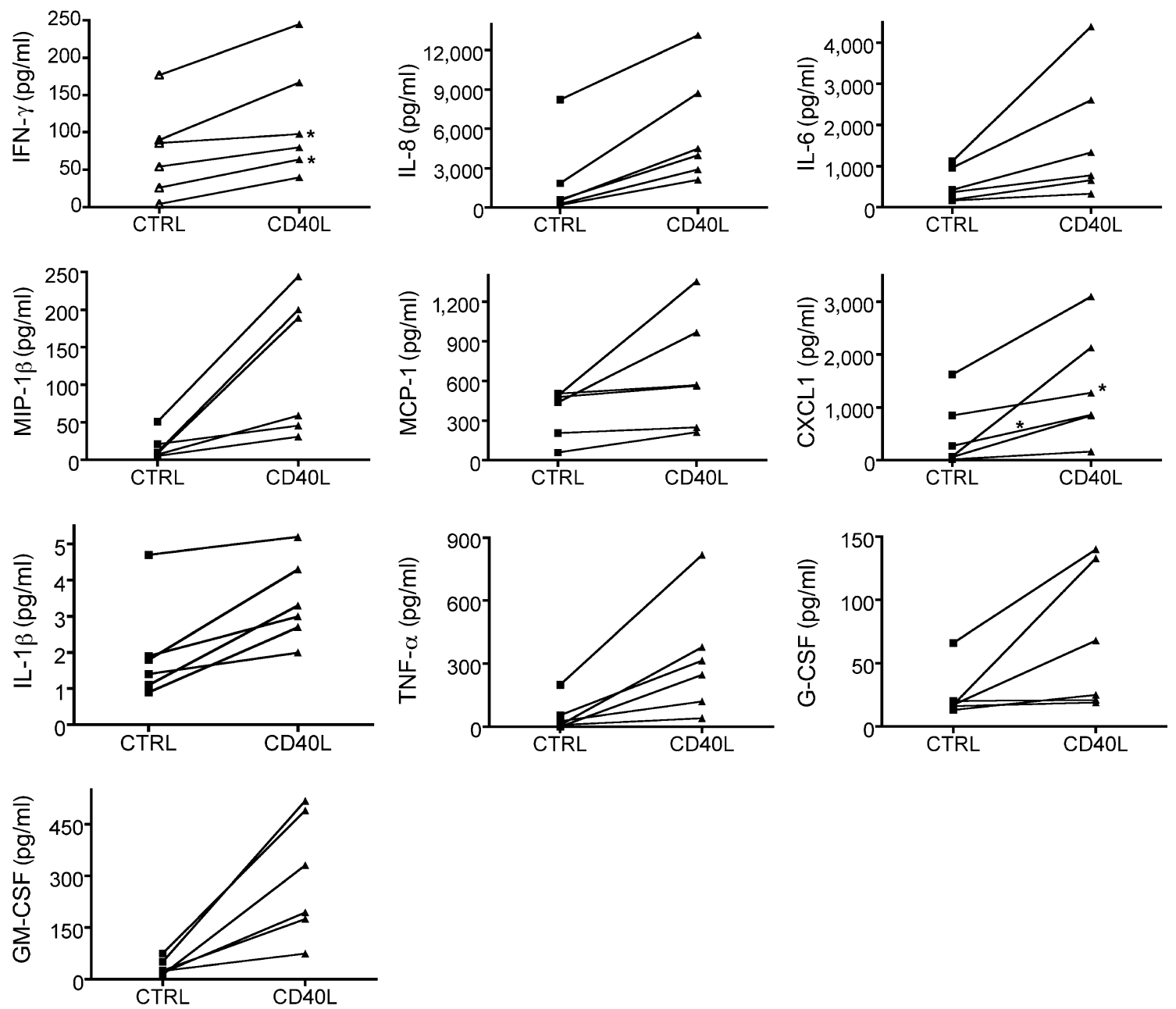

Fig. 4 Cytokine secretion profile of ductal cells activated with CD40L. Purified ductal cells were treated with CD40L for $24 \mathrm{~h}$. Supernatant fractions were analysed for cytokines. The values of the asterisk-labelled samples are represented as one-tenth of the actual

neutrophils in reperfused organs [32] and in inflammatory diseases (i.e. ulcerative colitis) has been documented [33, 34]. To the best of our knowledge we are the first to show a connection between CD40 activation and expression of the CXCL family of chemokines in pancreatic islet cells. CXCL1 transcription was induced by IL-1 $\beta$ in rat pancreatic beta cells [35] and in a $\mathrm{CD} 4^{+} \mathrm{T}$ cell receptor transgenic variant of the NOD mouse model of cyclophosphamidemediated diabetes [36]. After exposure to the type 2 diabetic milieu, murine and human islets secreted chemokine $\mathrm{KC}$ (mouse homologue of human CXCL1) and CXCL1, respectively [37]. A similar phenomenon was observed in islets isolated from mice kept on a high-fat diet [37]. Production of CXCL1 may have a role in protection, as is the case in islet interaction with extracellular matrix [20]. It has been postulated that the effect of CXCL1 on beta cells is controlled by the amplitude of signalling and by the prevailing biological context [20]. A recent report indicates that cytokines originally considered to be only value in order to be included in the same scale. The Wilcoxon signedrank test for paired, non-parametric samples was used for statistical analysis ( $p=0.031$ for all cytokines) $(n=6$ independent ductal cells preparations). CTRL, control

harmful, such as IL-1 $\beta$, could actually be beneficial. IL-1 $\beta$ in small quantities induces beta cell proliferation and protects pancreatic islets from receptor-mediated apoptosis [38]. In our gene array analysis, $I L 1 B$ was increased 14fold. However, we have not detected the cytokine in supernatant fractions of depleted islet cells [14]. The detection of IL-1 $\beta$ by ELISA-based methods has been reported as difficult. However, we have detected IL-1 $\beta$ in supernatant fractions of activated ductal cells. Therefore it is unlikely that the reported lack of IL-1 $\beta$ secretion in islet cells is due to a technical difficulty in its detection. The increase of RNA in our gene arrays could be false positives, or there could be a lack of correlation between RNA and protein expression, as was reported for other genes [39]. CD40-mediated chemokine secretion in vivo may have a detrimental effect on transplanted islets due to the recruitment of monocytes and macrophages at the site of implantation. In vitro, however, it is not the case. Our in vitro data indicate that CD40-mediated chemokine secre- 
tion did not significantly affect islet viability. These results are in agreement with a recent report describing only mild effects of $\mathrm{KC}$ on beta cell apoptosis and insulin secretion in murine islets [37]. Therefore, it is possible that the major threat does not lie in the cytokines/chemokines themselves but in their chemoattractant property in vivo, where immune cells are recruited to the site and damage the graft.

High glucose concentration results in the induction of the ERK1/2 pathway and stimulates secretion of insulin in MIN6 insulinoma cell line and rat pancreatic islets. The effect is partially obliterated by mitogen-activated protein kinase kinase inhibitor PD98059 [26]. Since one of the CD40 signalling pathways in islets is ERK1/2 [14], we investigated if activation of CD40 affects insulin secretion. We analysed insulin secretion by a perifusion method and did not find any difference between the profiles of $24 \mathrm{~h}$ CD40L-induced islets and untreated controls. Because both CD40L and glucose affect the same pathway, we had expected a synergistic effect of CD40L and glucose on insulin secretion. It is possible that the levels of ERK1/2 activation were not further increased by CD40L induction, resulting in the same amount of secreted insulin. Similar results were observed with $30 \mathrm{~min}$ of CD40L incubation, the time frame at which ERK1/2 activation persists in human islets (D. Klein and R. L. Pastori, unpublished observations).

Pancreatic ductal cells are a common 'contaminant' of human islet preparations and are co-transplanted with them. Pancreatic ductal cells contribute to cytokine responses of human islets by producing nitric oxide and TNF- $\alpha[40,41]$. Furthermore, ductal cells express constitutively CD40 and its activation induces NF- $\mathrm{kB}$-mediated transcription of $T N F \alpha$ and $I L 1 B$ in Capan2, the cell line derived from ductal cells, and secretion of TNF- $\alpha$ in both Capan 2 and primary pancreatic ductal cells [16]. In this study, we found that, unlike in islets, CD40 activation in ductal cells produces TNF- $\alpha$, IFN- $\gamma$ and IL- $1 \beta$, cytokines known to be deleterious in higher concentrations to human islet viability and function. However, we have discovered that upon CD40 stimulation ductal cells produce GM-CSF and G-CSF, which are key haematopoietic growth factors of the myeloid lineage, controlling production, differentiation and function of granulocytes and macrophages [42]. Both cytokines affect adaptive immune responses. G-CSF inhibits onset of diabetes in the cyclophosphamide-accelerated mouse model [43] and prevents beta cell destruction [44]. G-CSF and GMCSF prevent onset of diabetes in NOD mice by inducing tolerogenic dendritic cells that sustain the function of regulatory $\mathrm{T}$ cells $[45,46]$. It is possible that production of GM-CSF and G-CSF contributes to the observed positive correlation between the number of ductal cells in islets graft and the outcome of the transplantation [47].
Acknowledgements This work was supported in part by NIH Islet Cell Resources grant 5U42RR016603, JDRF International grant 42004-361 and the Diabetes Research Institute Foundation. We thank A. Pileggi for critical reading of the manuscript.

Duality of interest The authors declare that there is no duality of interest associated with this manuscript.

\section{References}

1. van Kooten C, Banchereau J (2000) CD40-CD40 ligand. J Leukoc Biol 67:2-17

2. Parker DC, Greiner DL, Phillips NE et al (1995) Survival of mouse pancreatic islet allografts in recipients treated with allogeneic small lymphocytes and antibody to CD40 ligand. Proc Natl Acad Sci USA 92:9560-9564

3. Balasa B, Krahl T, Patstone G et al (1997) CD40 ligand-CD40 interactions are necessary for the initiation of insulitis and diabetes in nonobese diabetic mice. J Immunol 159:4620-4627

4. Molano RD, Berney T, Li H et al (2001) Prolonged islet graft survival in NOD mice by blockade of the CD40-CD154 pathway of $\mathrm{T}$ cell costimulation. Diabetes 50:270-276

5. Kenyon NS, Chatzipetrou M, Masetti M et al (1999) Long-term survival and function of intrahepatic islet allografts in rhesus monkeys treated with humanized anti-CD154. Proc Natl Acad Sci U S A 96:8132-8137

6. Zirlik A, Bavendiek U, Libby P et al (2007) TRAF-1, -2, -3, -5, and -6 are induced in atherosclerotic plaques and differentially mediate proinflammatory functions of CD40L in endothelial cells. Arterioscler Thromb Vasc Biol 27:1101-1107

7. Alabraba EB, Lai V, Boon L, Wigmore SJ, Adams DH, Afford SC (2008) Coculture of human liver macrophages and cholangiocytes leads to CD40-dependent apoptosis and cytokine secretion. Hepatology 47:552-562

8. Ohta Y, Hamada Y (2004) In situ expression of CD40 and CD40 ligand in psoriasis. Dermatology 209:21-28

9. Smith TJ, Sciaky D, Phipps RP, Jennings TA (1999) CD40 expression in human thyroid tissue: evidence for involvement of multiple cell types in autoimmune and neoplastic diseases. Thyroid 9:749-755

10. Falco A, Romano M, Iapichino L, Collura M, Davi G (2004) Increased soluble CD40 ligand levels in cystic fibrosis. J Thromb Haemost 2:557-560

11. Eeva J, Ropponen A, Nuutinen U et al (2007) The CD40-induced protection against CD95-mediated apoptosis is associated with a rapid upregulation of anti-apoptotic c-FLIP. Mol Immunol 44:1230-1237

12. Laxmanan S, Datta D, Geehan C, Briscoe DM, Pal S (2005) CD40: a mediator of pro- and anti-inflammatory signals in renal tubular epithelial cells. J Am Soc Nephrol 16:2714-2723

13. Klein D, Barbe-Tuana F, Pugliese A et al (2005) A functional CD40 receptor is expressed in pancreatic beta cells. Diabetologia 48:268-276

14. Barbe-Tuana FM, Klein D, Ichii $\mathrm{H}$ et al (2006) CD40-CD40 ligand interaction activates proinflammatory pathways in pancreatic islets. Diabetes 55:2437-2445

15. Sligh JE Jr, Ballantyne CM, Rich SS et al (1993) Inflammatory and immune responses are impaired in mice deficient in intercellular adhesion molecule 1. Proc Natl Acad Sci U S A 90:8529-8533

16. Vosters O, Beuneu C, Nagy N et al (2004) CD40 expression on human pancreatic duct cells: role in nuclear factor-kappa B 
activation and production of pro-inflammatory cytokines. Diabetologia 47:660-668

17. Ricordi C, Lacy PE, Finke EH, Olack BJ, Scharp DW (1988) Automated method for isolation of human pancreatic islets. Diabetes 37:413-420

18. Tusher VG, Tibshirani R, Chu G (2001) Significance analysis of microarrays applied to the ionizing radiation response. Proc Natl Acad Sci U S A 98:5116-5121

19. Khatri P, Draghici S, Ostermeier GC, Krawetz SA (2002) Profiling gene expression using onto-express. Genomics 79:266-270

20. Ribaux P, Ehses JA, Lin-Marq N et al (2007) Induction of CXCL1 by extracellular matrix and autocrine enhancement by interleukin-1 in rat pancreatic beta-cells. Endocrinology 148:5582-5590

21. Sachse F, von Eiff C, Stoll W, Becker K, Rudack C (2006) Induction of CXC chemokines in A549 airway epithelial cells by trypsin and staphylococcal proteases: a possible route for neutrophilic inflammation in chronic rhinosinusitis. Clin Exp Immunol 144:534-542

22. Shattuck RL, Wood LD, Jaffe GJ, Richmond A (1994) MGSA/ GRO transcription is differentially regulated in normal retinal pigment epithelial and melanoma cells. Mol Cell Biol 14:791-802

23. Ping L, Ogawa N, Sugai S (2005) Novel role of CD40 in Fasdependent apoptosis of cultured salivary epithelial cells from patients with Sjogren's syndrome. Arthritis Rheum 52:573-581

24. Szocinski JL, Khaled AR, Hixon J et al (2002) Activation-induced cell death of aggressive histology lymphomas by CD40 stimulation: induction of bax. Blood 100:217-223

25. Georgopoulos NT, Merrick A, Scott N, Selby PJ, Melcher A, Trejdosiewicz LK (2007) CD40-mediated death and cytokine secretion in colorectal cancer: a potential target for inflammatory tumour cell killing. Int J Cancer 121:1373-1381

26. Longuet C, Broca C, Costes S, Hani EH, Bataille D, Dalle S (2005) Extracellularly regulated kinases 1/2 (p44/42 mitogenactivated protein kinases) phosphorylate synapsin I and regulate insulin secretion in the MIN6 beta-cell line and islets of Langerhans. Endocrinology 146:643-654

27. Furuzawa-Carballeda J, Vargas-Rojas MI, Cabral AR (2007) Autoimmune inflammation from the Th17 perspective. Autoimmun Rev 6:169-175

28. Ahuja SK, Murphy PM (1996) The CXC chemokines growth-regulated oncogene (GRO) alpha, GRObeta, GROgamma, neutrophil-activating peptide-2, and epithelial cell-derived neutrophil-activating peptide-78 are potent agonists for the type B, but not the type A, human interleukin-8 receptor. J Biol Chem 271:20545-20550

29. Ludwig A, Petersen F, Zahn S et al (1997) The CXC-chemokine neutrophil-activating peptide-2 induces two distinct optima of neutrophil chemotaxis by differential interaction with interleukin-8 receptors CXCR-1 and CXCR-2. Blood 90:4588-4597

30. Geiser T, Dewald B, Ehrengruber MU, Clark-Lewis I, Baggiolini M (1993) The interleukin-8-related chemotactic cytokines GRO alpha, GRO beta, and GRO gamma activate human neutrophil and basophil leukocytes. J Biol Chem 268:15419-15424

31. Haskill S, Peace A, Morris J et al (1990) Identification of three related human GRO genes encoding cytokine functions. Proc Natl Acad Sci U S A 87:7732-7736

32. Miura M, Fu X, Zhang QW, Remick DG, Fairchild RL (2001) Neutralization of Gro alpha and macrophage inflammatory protein-2 attenuates renal ischemia/reperfusion injury. Am J Pathol 159:2137-2145

33. Egesten A, Eliasson M, Olin AI et al (2007) The proinflammatory CXC-chemokines GRO-alpha/CXCL1 and MIG/CXCL9 are concomitantly expressed in ulcerative colitis and decrease during treatment with topical corticosteroids. Int $\mathrm{J}$ Colorectal Dis 22:1421-1427

34. Mitsuyama K, Tsuruta O, Tomiyasu N et al (2006) Increased circulating concentrations of growth-related oncogene (GRO)alpha in patients with inflammatory bowel disease. Dig Dis Sci 51:173-177

35. Chen MC, Schuit F, Eizirik DL (1999) Identification of ILlbeta-induced messenger RNAs in rat pancreatic beta cells by differential display of messenger RNA. Diabetologia 42:11991203

36. Matos M, Park R, Mathis D, Benoist C (2004) Progression to islet destruction in a cyclophosphamide-induced transgenic model: a microarray overview. Diabetes 53:2310-2321

37. Ehses JA, Perren A, Eppler E et al (2007) Increased number of islet-associated macrophages in type 2 diabetes. Diabetes $56: 2356-2370$

38. Maedler K, Schumann DM, Sauter N et al (2006) Low concentration of interleukin-1beta induces FLICE-inhibitory protein-mediated beta-cell proliferation in human pancreatic islets. Diabetes 55:2713-2722

39. Misra RR, Crance KA, Bare RM, Waalkes MP (1997) Lack of correlation between the inducibility of metallothionein mRNA and metallothionein protein in cadmium-exposed rodents. Toxicology 117:99-109

40. Pavlovic D, Chen MC, Bouwens L, Eizirik DL, Pipeleers D (1999) Contribution of ductal cells to cytokine responses by human pancreatic islets. Diabetes 48:29-33

41. Movahedi B, Van de Casteele M, Caluwe N et al (2004) Human pancreatic duct cells can produce tumour necrosis factor-alpha that damages neighbouring beta cells and activates dendritic cells. Diabetologia 47:998-1008

42. Metcalf D (2008) Hematopoietic cytokines. Blood 111:485-491

43. Hadaya K, Kared H, Masson A, Chatenoud L, Zavala F (2005) G-CSF treatment prevents cyclophosphamide acceleration of autoimmune diabetes in the NOD mouse. J Autoimmun 24:125-134

44. Enzler T, Gillessen S, Dougan $M$ et al (2007) Functional deficiencies of granulocyte-macrophage colony stimulating factor and interleukin-3 contribute to insulitis and destruction of beta cells. Blood 110:954-961

45. Kared H, Masson A, Adle-Biassette H, Bach JF, Chatenoud L, Zavala F (2005) Treatment with granulocyte colony-stimulating factor prevents diabetes in NOD mice by recruiting plasmacytoid dendritic cells and functional $\mathrm{CD} 4(+) \mathrm{CD} 25(+)$ regulatory T cells. Diabetes 54:78-84

46. Gaudreau S, Guindi C, Menard M, Besin G, Dupuis G, Amrani A (2007) Granulocyte-macrophage colony-stimulating factor prevents diabetes development in NOD mice by inducing tolerogenic dendritic cells that sustain the suppressive function of CD4+CD25+ regulatory T cells. J Immunol 179:3638-3647

47. Street CN, Lakey JR, Shapiro AM et al (2004) Islet graft assessment in the Edmonton Protocol: implications for predicting long-term clinical outcome. Diabetes 53:3107-3114 